\title{
ANALYSIS OF REFLECTION COEFFICIENT OF ARTERY : THE DISTANCE DEPENDENCY AND ISOLATED EFFECTS OF CHANGES IN RADIUS AND ELASTIC MODULUS OF ARTERIAL WALL
}

\author{
H. HIRAYAMA* Y. FUKUYAMA*
}

\begin{abstract}
Arterial Reflection Coefficient has been analyzed systematically to elucidate the influence of the distance from the entry zone of artery in combination with isolated effects of radius and elastic modulus of arterial wall with the help of transmission line theory. The femoral artery was selected as a target because its geometrical constancy enabled the problem solvable. The dynamical features of blood flow and wall motion have been described by two sets of differential equations. They were converted to transmission line equations by assuming linear cyclic solutions. The reflection coefficient was obtained by setting terminal boundary conditions and complex analysis utilizing the transmission coefficient.

The reflection coefficient increased with distance from the entry zone. A rapid increase manifested at near the terminal while the change was gradual at the entrance zone. The reflection coefficient was small in magnitude at large radius while it marked a large value at large elastic modulus. Present data has been compared qualitatively with reported physical experimental data of pressure wave reflection in rubber tube under the physiological condition which were identical with ours. As long as the law of a quarter wave length operates, present theoretical analysis is valid quantitatively and qualitatively. Present results would be available for creating more physiological artificial vessel.
\end{abstract}

\section{[ INTRODUCTION]}

Several biophysical quantities have been utilized to describe the functional properties of arterial system relating to the pulsatile nature of blood flow transmission (Womersely 1957). Among them, the pulse wave reflection is the most striking mechanical characterization of pulse transmission in arterial tree. In arterial system, observed pressure and flow waves are the sum of incident and reflected waves that vary in amplitude as functions of distance (MacDonald 1974). The reflection coefficient is one of the indices that can describe the mechanical aspects of pulse reflection in the spatial domain. It, however, has been scarcely investigated experimentally nor theoretically because not only biophysical factors such as visco-elastic properties of arterial wall, internal radius and tethering from surrounding tissue but also geometric factors such as

1994 年 6 月27日受付

* THE DEPARTMENT OF PUBLIC HEALTH,

ASAHIKAWA MEDICAL COLLEGE.

Key words : Reflection Coefficient, Radius, Elastic Modulus, Tapering, Wave Length, Artificial Vessel. branching and tapering have made it intractable. Further the elastic modulus and radius change consecutively (distance dependency) because of the tapering of arterial system. Thus, the vital deficit in older investigations was the lack of its distance dependency from the entry zone of arterial tree and the isolated effects of elastic modulus and radius.

In the present investigation, we approach quantitatively the reflection coefficient by theoretical method because such approach can isolate and make clear the independent effects of elastic properties of arterial wall and radius on reflection coefficient which change depending on the distance in an actual arterial system. A particular emphasis has been put on the distance dependency of reflection coefficient to elucidate how it varies at different positions of arterial segment.

\section{[ MATHEMATICAL PROCESS ]}

For the simplicity of analysis and to elucidate focus of reflection, investigation is confined to an artery whose radius is relatively constant ( $\mathrm{Li} \mathrm{1981)}$, having no branch with one terminal ending. The femoral artery is the most suit- 
able example. To describe the pulsatile blood flow in arterial system, two sets of differential equations are required. First one is the Navier-Stokes equations that describe the fluid dynamical properties of arterial flow. For the simplicity, flow is assumed to be cylindrically symmetric and the pulse wave length is sufficiently large to ignore the nonlinear terms in the equations ( Sakamoto, 1967). Thus

$$
\begin{aligned}
& \frac{\partial \mathrm{V}}{\partial \mathrm{t}}=-\frac{1}{\rho} \frac{\partial \mathrm{P}}{\partial \mathrm{r}}+\frac{\mu}{\rho}\left[\frac{\partial^{2} \mathrm{~V}}{\partial \mathrm{z}^{2}}+\frac{1}{\mathrm{r}} \frac{\partial \mathrm{V}}{\partial \mathrm{r}}+\frac{\partial^{2} \mathrm{~V}}{\partial \mathrm{r}^{2}}-\frac{\mathrm{V}}{\mathrm{r}^{2}}\right] \\
& \frac{\partial \mathrm{W}}{\partial \mathrm{t}}=-\frac{1}{\rho} \frac{\partial \mathrm{P}}{\partial \mathrm{z}}+\frac{\mu}{\rho}\left[\frac{\partial^{2} \mathrm{~W}}{\partial \mathrm{z}^{2}}+\frac{1}{\mathrm{r}} \frac{\partial \mathrm{W}}{\partial \mathrm{r}}+\frac{\partial^{2} \mathrm{~W}}{\partial \mathrm{r}^{2}}\right] \\
& \frac{\partial \mathrm{V}}{\partial \mathrm{r}}+\frac{\mathrm{V}}{\mathrm{r}}+\frac{\partial \mathrm{W}}{\partial \mathrm{z}}=0
\end{aligned}
$$

where $\rho$ : density of the blood $\left(=1.003 \mathrm{~g} / \mathrm{cm}^{3}\right), \mu$ : viscosity of the blood ( $=0.03$ Poiseuille), $\mathrm{W}$ : blood flow velocity along the arterial axis, $\mathrm{V}$ : velocity in radial direction, $\mathrm{P}$ : input blood pressure, $\mathrm{z}$ : longitudinal axis, $r$ : radial axis. Equation (3) expresses the conservative law. The dynamical equations of arterial wall including tethering from surrounding tissue are

$$
\begin{aligned}
& \rho 0 \frac{\partial^{2} \xi}{\partial \mathrm{t}^{2}}+\mathrm{CI} \frac{\partial \xi}{\partial \mathrm{t}}+\mathrm{KI} \xi= \\
& \frac{\mathrm{h}}{\mathrm{H}} \frac{\mathrm{Et}}{1-\sigma \theta}\left(\frac{\partial^{2} \xi}{\partial \mathrm{z}^{2}}+\frac{\sigma \theta}{\mathrm{R}_{\mathrm{a}}} \frac{\partial \eta}{\partial \mathrm{z}}\right)-\frac{\mu}{\mathrm{H}}\left[\frac{\partial \mathrm{W}}{\partial \mathrm{r}}+\frac{\partial \mathrm{V}}{\partial \mathrm{z}}\right] \\
& \rho \circ \frac{\partial^{2}}{\partial \mathrm{t}^{2}}+\mathrm{Cr} \frac{\partial \eta}{\partial \mathrm{t}}+\mathrm{Kr} \eta= \\
& -\frac{\mathrm{h}}{\mathrm{H}} \frac{\mathrm{E} \theta}{1-\sigma \mathrm{t} \sigma \theta}\left(\frac{\eta}{\mathrm{R}_{\mathrm{a}}^{2}}+\frac{\sigma \mathrm{t}}{\mathrm{R}_{\mathrm{a}}} \frac{\partial \xi}{\partial \mathrm{t}}\right)+\left[\frac{\mathrm{P}}{\mathrm{H}}-\frac{2 \mu}{\mathrm{H}} \frac{\partial \mathrm{V}}{\partial \mathrm{r}}\right]
\end{aligned}
$$

where $\zeta$ : axial displacement of wall, $\eta$ : radial displacement of wall. The properties of surrounding tissue can be decomposed into inertance, viscosity and elasticity in longitudinal and radial directions (Patel, 1966). We express them by $\rho \mathrm{o}:$ density of the surrounding tissue, $\mathrm{Cl}:$ the viscous coefficient, $\mathrm{Kl}$ : the elastic coefficient in longitudinal direction while $\mathrm{Cr}$ and $\mathrm{Kr}$ are their radial components. The arteral wall properties are expressed by Et : dynamic elastic modulus in axial direction, $\mathrm{E} \theta$ : dynamic elastic modulus in circumferential direction, $\sigma \mathrm{t}:$ Poisson ratio in axial direction and $\sigma \theta$ : Poisson ratio in circumferential direction, $\mathrm{h}$ : arterial wall thickness, $\mathrm{H}$ : thickness of interstitial surrounding tissue. $\mathrm{Ra}$ is internal radius of artery. The left sides of equations represent forces from surrounding tissue to constrict the wall motion while right sides express elastic forces in arterial wall and viscous retardation force by blood flow. Then, we set following linear cyclic solutions with $\omega=2 \pi \mathrm{f}, \mathrm{C}$ : the pulse wave velocity,

$$
\begin{aligned}
& P=P(r) \exp (i \omega(t-z / C)) \\
& W=V z(r) \exp (i \omega(t-z / C)) \\
& V=V r(r) \exp (i \omega(t-z / C)) \\
& \zeta=D \quad \exp (i \omega(t-z / C)) \\
& \eta=E \quad \exp (i \omega(t-z / C))
\end{aligned}
$$

The boundary conditions at the internal surface of arterial wall require that the motions of blood and wall must be identical without slipping. Thus at $r=\mathrm{Ra}$,

$$
\begin{aligned}
& \frac{\partial \xi}{\partial \mathrm{t}}=\mathrm{W} \\
& \frac{\partial \eta}{\partial \mathrm{t}}=\mathrm{V}
\end{aligned}
$$

Under the physiological pressure range and loading condition, arterial wall can be assumed to be isotropic (Tickner, 1967) $\mathrm{Et}=\mathrm{E} \theta$, and incompressible (Carew, 1968) $\sigma \theta=$ $\sigma \mathrm{t}=0.5$. The effect of surrounding tissue can be represented by the longitudinal elastic effect, KI (Patel 1967). Consequently, the equations (1) to (5) are transformed to transmission line equations (see APPENDIX). Couverting pressure to voltage $\mathrm{V}(\mathrm{x})$, flow to current $\mathrm{I}(\mathrm{x})$, the solutions are

$$
\begin{aligned}
& \mathrm{V}(\mathrm{x})=\mathrm{K} 1 \exp (-\gamma \mathrm{x})+\mathrm{K} 2 \exp (\gamma \mathrm{x}) \ldots \ldots \ldots \\
& \mathrm{I}(\mathrm{x})=(\mathrm{K} 1 \exp (-\gamma \mathrm{x})-\mathrm{K} 2 \exp (\gamma \mathrm{x})) / \mathrm{Zo}
\end{aligned}
$$

where $\gamma=((R+i \omega L) C p)$ is the transmission coefficient and $Z_{0}=((R+i \omega L) /(i \omega C p))$ is the characteristic impedance. Here, $\mathrm{L}$ is inertance, $\mathrm{R}$ is resistance, $\mathrm{C}$ is compliance and they are functions of $\omega$. From the definition of reflection

$$
\text { Reflection Coefficient }=\mathrm{K} 2 \exp (\gamma \mathrm{x}) / \mathrm{K} 1 \exp (-\gamma \mathrm{x})
$$




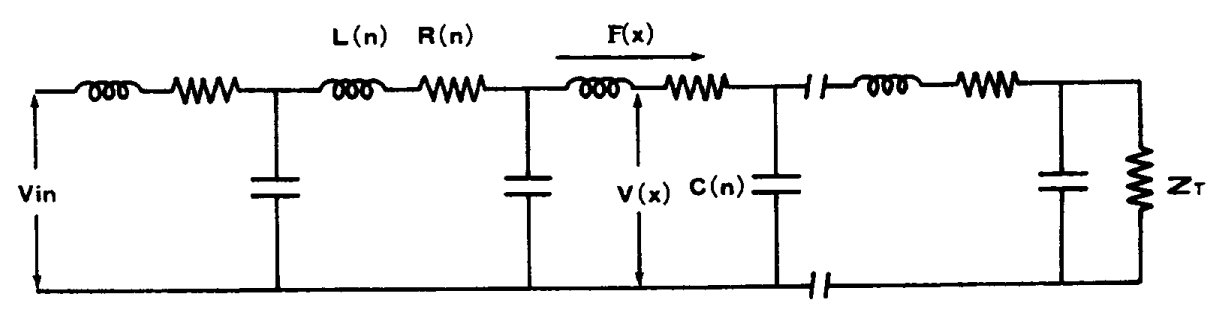

Fig 1. An equivalent electrical circuit of a segmental artery in the present theoretical analysis.

The unknown coefficient $\mathrm{K} 1$ and $\mathrm{K} 2$ are determined by setting the terminal impedance ZT at the end of transmission line. For $x=L$ (total length), we set $V(x=L)$ and $I$ $(x=L)$ as the pressure and flow at the end of arterial tube,

$$
\mathrm{ZT}=\mathrm{V}(\mathrm{x}=\mathrm{L}) / \mathrm{I}(\mathrm{x}=\mathrm{L})=3600 \mathrm{~g} / \mathrm{cm}^{4} \mathrm{sec}
$$

\section{Thus}

$$
\mathrm{K} 1 / \mathrm{K} 2=(\mathrm{ZT}+\mathrm{Zo}) \exp (2 \gamma \mathrm{L}) /(\mathrm{ZT}-\mathrm{Zo})
$$

Then the reflection coefficient can be obtained by complex analysis. Fig 1 shows an equivalent electrical transmission line for present investigation. To elucidate the isolated effects of radius, $R$ a has been changed from $0.2 \mathrm{~cm}$ to $0.32 \mathrm{~cm}$. To avoid the complication, only the first harmonic of the dynamic elastic modulus $\mathrm{Ed}(\mathrm{f}=1)(=\mathrm{Et}=$ $\mathrm{E} \theta$ ) has been changed from $4 \cdot 10^{6} \mathrm{~g} / \mathrm{cm} / \mathrm{sec}^{2}$ to $30 \cdot 10^{6}$ $\mathrm{g} / \mathrm{cm} / \mathrm{sec}^{2}$ while all other harmonics have been set to be $30 \cdot 10^{6} \mathrm{~g} / \mathrm{cm} / \mathrm{sec}^{2}$ ( Learoyd 1966 ). For the simplicity of analysis, we set $\mathrm{h}=\mathrm{H}=0.025 \mathrm{~cm}, \mathrm{KI}=10^{5}, \mathrm{Cl}=50$ (Atabeck 1968), $\mathrm{Kr}=\mathrm{Cr}=0$ and $\rho=\rho$ o. To emphasize the distance dependency of the reflection coefficient, the total length of artery $\mathrm{L}$ has been set to be $60 \mathrm{~cm}$ which, however, is sufficiently shorter than a wave length at any combined changes in radius and elastic modulus.

\section{[ RESULTS ]}

1. The effects of distance from the entry zone of arterial tube with parametric changes in radius $\mathrm{Ra}$.

Figure 2 shows the changes in the first harmonic component of the reflection coefficient (Ref. Coef) as a function of distance $x$ from the entry zone of arterial tube at lower $\left(\operatorname{Ed}(\mathrm{f}=1)=8 \cdot 10^{6} \mathrm{~g} / \mathrm{cm} / \mathrm{sec}^{2}\right)$ first harmonic of elastic modulus Ed (Fig2-a) and at higher $\left(\mathrm{Ed}(\mathrm{f}=1)=20 \cdot 10^{6} \mathrm{~g} / \mathrm{cm} / \mathrm{sec}^{2}\right.$ ) one (Fig 2-b) where the harmonic components of dynamic elastic modulus are shown in raw matrix. The internal radius has been set to change parametrically from $0.2 \mathrm{~cm}$ to $0.3 \mathrm{~cm}$. In both magnitudes of elastic modulus $\mathrm{Ed}$ $(\mathrm{f}=1)$, the Reflection Coefficient increased with $\mathrm{x}$. At near the entry zone $(0 \mathrm{~cm}<x<20 \mathrm{~cm})$, the reflection coefficient increased gradually while at near the terminal of arterial segment, it increased rapidly. Thus, incremental ratio of reflection coefficient distributed unevenly at entire length of arterial tube. This tendency was evident particularly at smaller radius and smaller $\operatorname{Ed}(\mathrm{f}=1)=8 \cdot 10^{6} \mathrm{~g} / \mathrm{cm} / \mathrm{sec}^{2}$ (Fig 2-a ). At a given position of arterial tube, the reflection coefficient marked a higher value at smaller radius than at larger one. At near the entry zone, the difference in the reflection coefficient due to radius was smaller than that at near the terminal. The effect of difference in radius was enhanced at near the terminal of artery and at lower $\operatorname{Ed}(\mathrm{f}=1)=8 \cdot 10^{6} \mathrm{~g} / \mathrm{cm} / \mathrm{sec}^{2}$.

2. The effects of $x$ with parametric change in elastic modulus $\operatorname{Ed}(\mathrm{f}=1)$.

Fig 3 shows the reflection coefficient with parametric changes in the elastic modulus $\operatorname{Ed}(\mathrm{f}=1)$. At smaller radius (Fig 3-a) $=0.223 \mathrm{~cm}$, with the lowest $\operatorname{Ed}(\mathrm{f}=1)$ $=8 \cdot 10^{6} \mathrm{~g} / \mathrm{cm} / \mathrm{sec}^{2}$, the reflection coefficient increased discontinuously. With increase in $\operatorname{Ed}(f=1)$, however, it increased almost linearly and the incremental ratio was evenly distributed at entire arterial tube. At larger radius $R a=0.3 \mathrm{~cm}$ (Fig 3-b), the distance dependent increase in reflection coefficient was markedly depressed and reflection coefficient was lower in magnitude than that in smaller radius.

3. The effect of changes in radius with parametric changes in distance $x$.

Fig 4 elucidates the quantitative effects of changes in radius on the reflection coefficient at lower elastic modulus $\operatorname{Ed}(f=1)=12 \cdot 10^{6} \mathrm{~g} / \mathrm{cm} / \mathrm{sec}^{2}$ (Fig 4-a) and at higher one $\operatorname{Ed}(f=1)=30 \cdot 10^{6} \mathrm{~g} / \mathrm{cm} / \sec ^{2}$ (Fig 4-b). With 
Ref Coef $(f=1)$ vs $X$

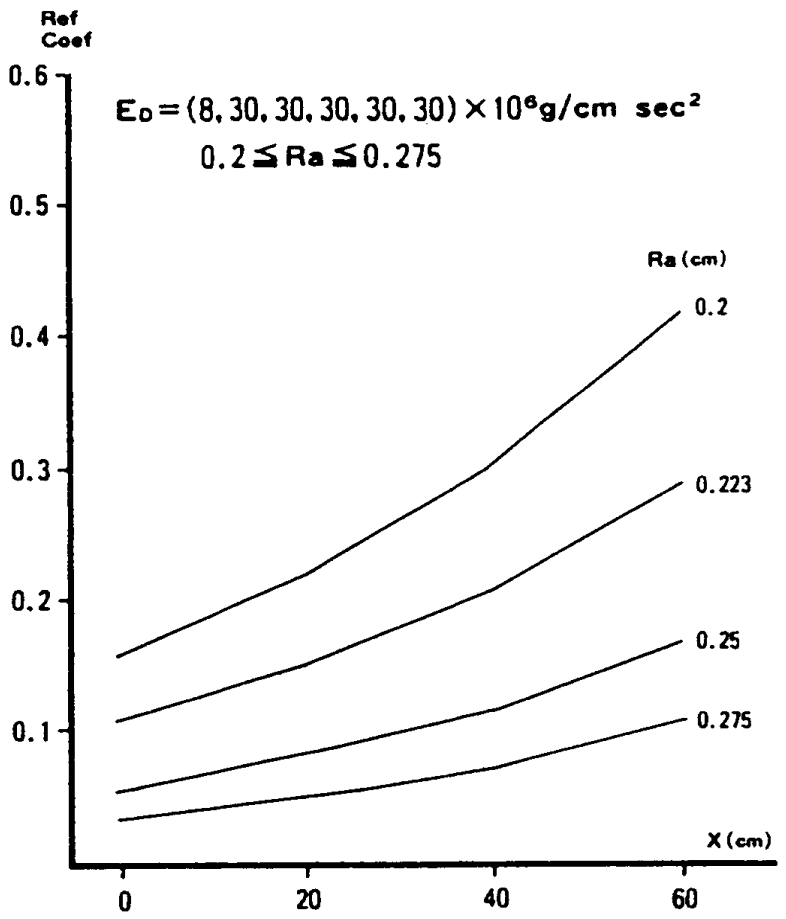

Fig 2-a
Ref Coef $(f=1)$ vs $X$

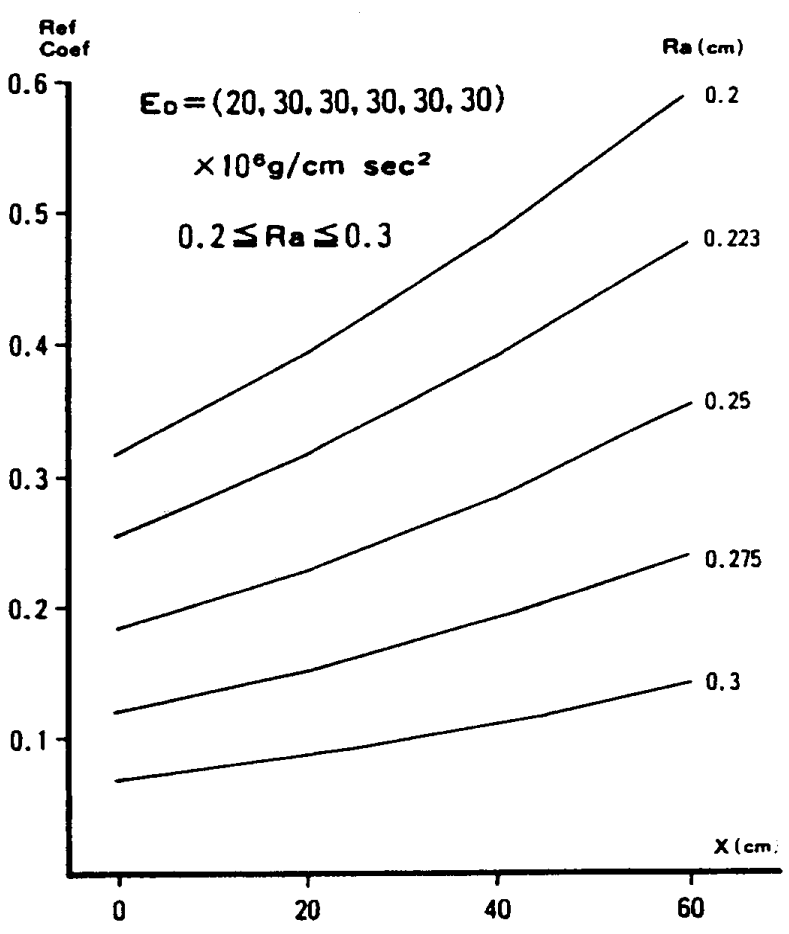

Fig 2-b

Fig 2. Reflection Coefficient and the distance from the entry zone $x$ with parametric change in radius Ra. Fig 2-a is calculated at elastic modulus of $\operatorname{Ed}(\mathrm{f}=1)=8 \cdot 10^{6} \mathrm{~g} / \mathrm{cm} / \mathrm{sec}^{2}$ and Fig 2-b is calculated at $\operatorname{Ed}(\mathrm{f}=1)=20 \cdot 10^{6} \mathrm{~g} / \mathrm{cm} / \mathrm{sec}^{2}$

Ref $\operatorname{Coef}(f=1)$ vs $x$

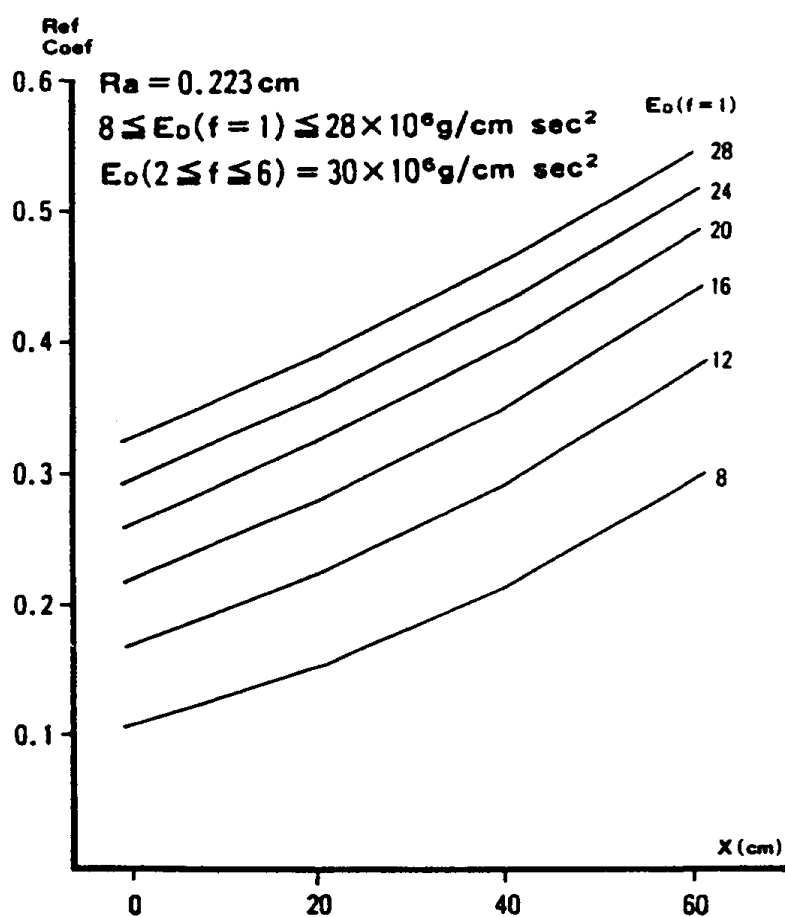

Fig 3-a
Ref Coef $(f=1)$ vs $X$

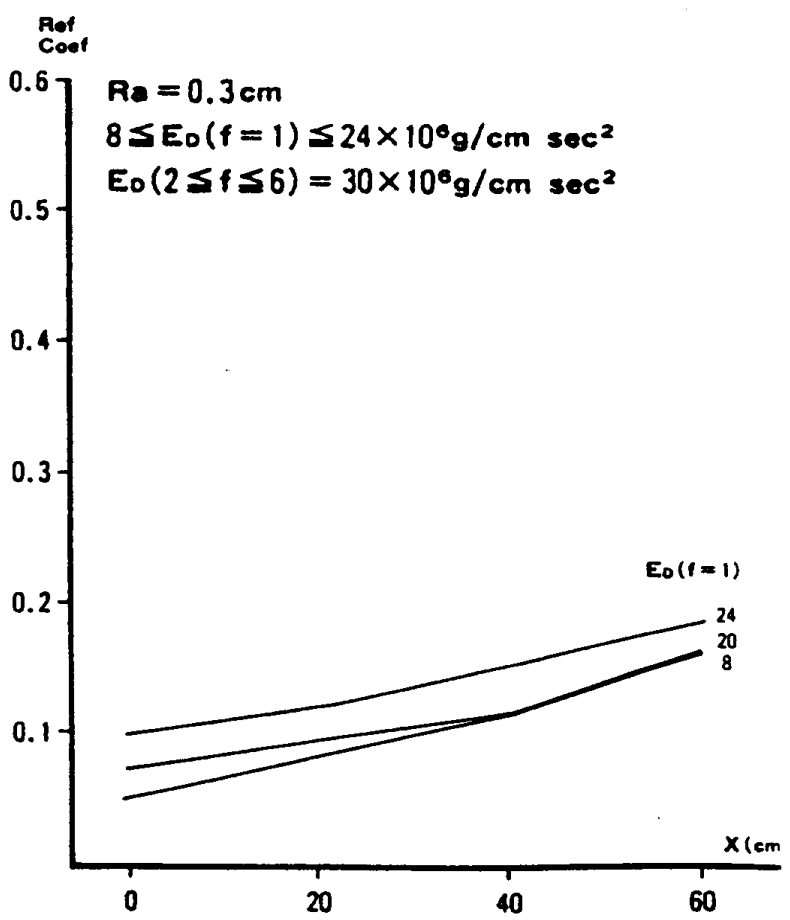

Fig 3-b

Fig 3. Reflection Coefficient and $x$ with parametric changes in elastic modulus $E d(f=1)$ at $\operatorname{Ra}=0.223 \mathrm{~cm}$ (Fig $3-a)$ and $R a$ $=0.3 \mathrm{~cm}$ (Fig 3-b). 
Ref Coef $(f=1)$ vs Ra

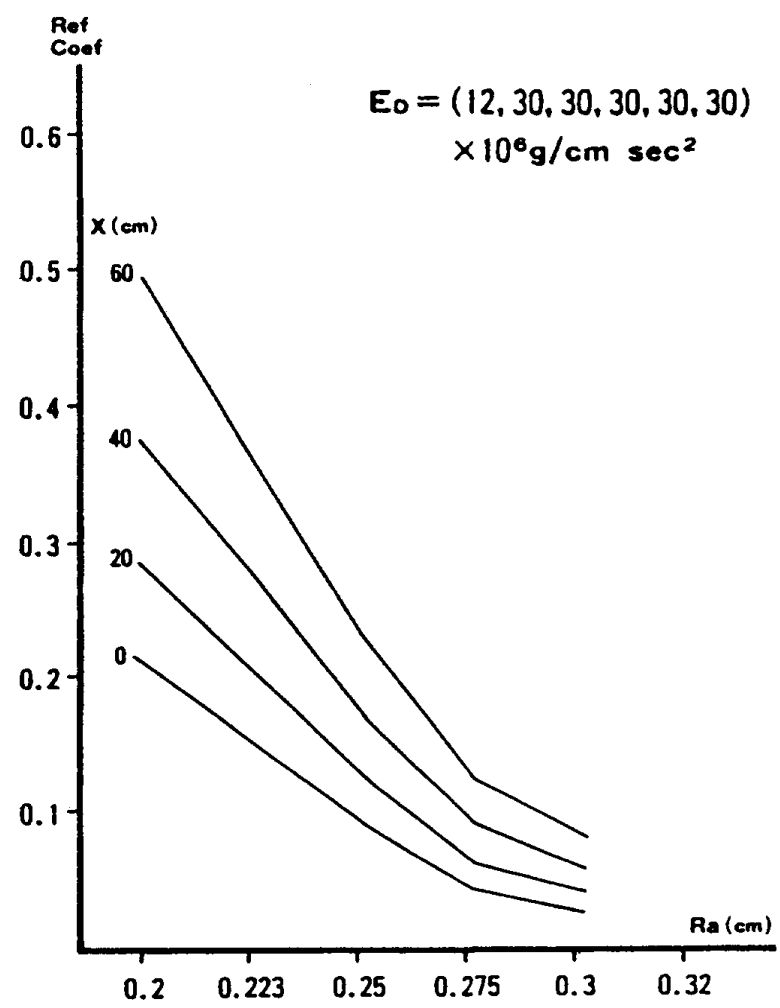

Fig 4-a
Ref Coef $(f=1)$ vs Ra

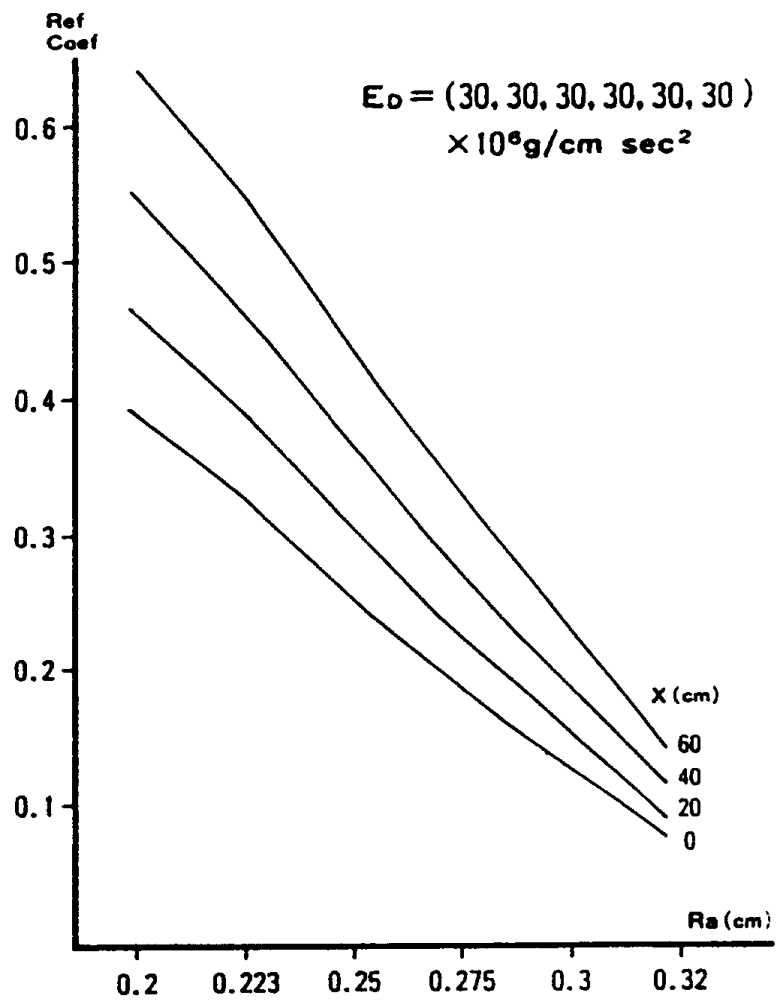

Fig 4-b

Fig 4. The quantitative effects of radius Ra on the Reflection Coefficient with parametric changes in $\mathrm{x}$ at elastic modulus Ed $(f=1)=12 \cdot 10^{6} \mathrm{~g} / \mathrm{cm} / \mathrm{sec}^{2}$ (Fig 4-a ) and $\operatorname{Ed}(f=1)=30 \cdot 10^{6} \mathrm{~g} / \mathrm{cm} / \mathrm{sec}^{2}$ (Fig 4-b).

Ref Coef $(f=1)$ vs Ra

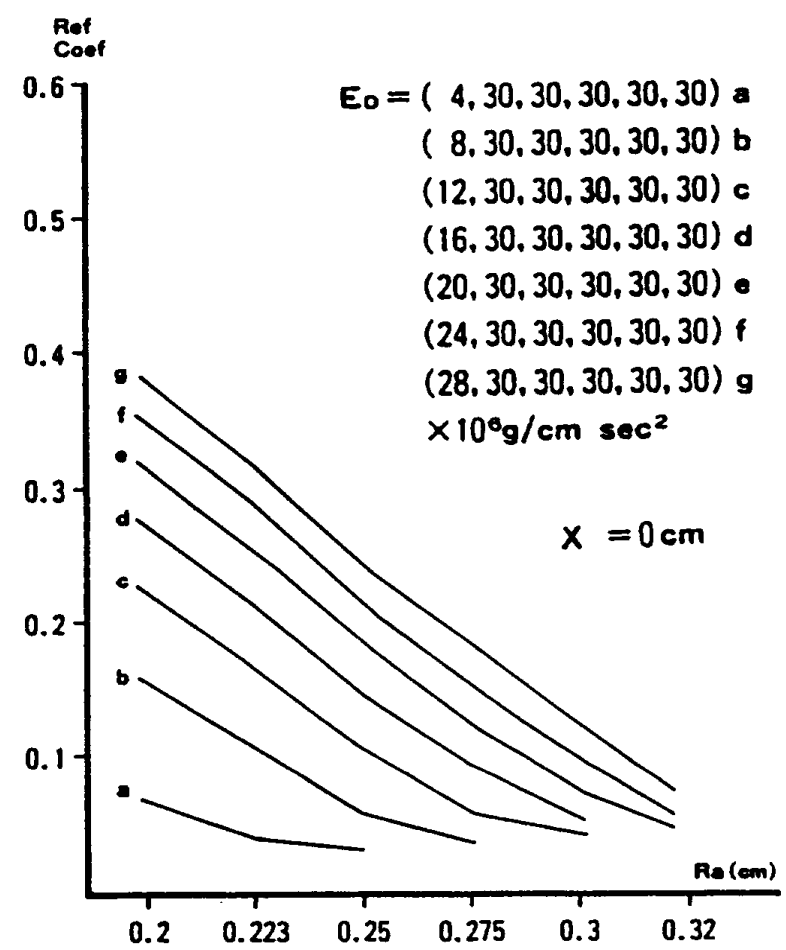

Fig 5-a
Ref Coef $(f=1)$ vs Ra

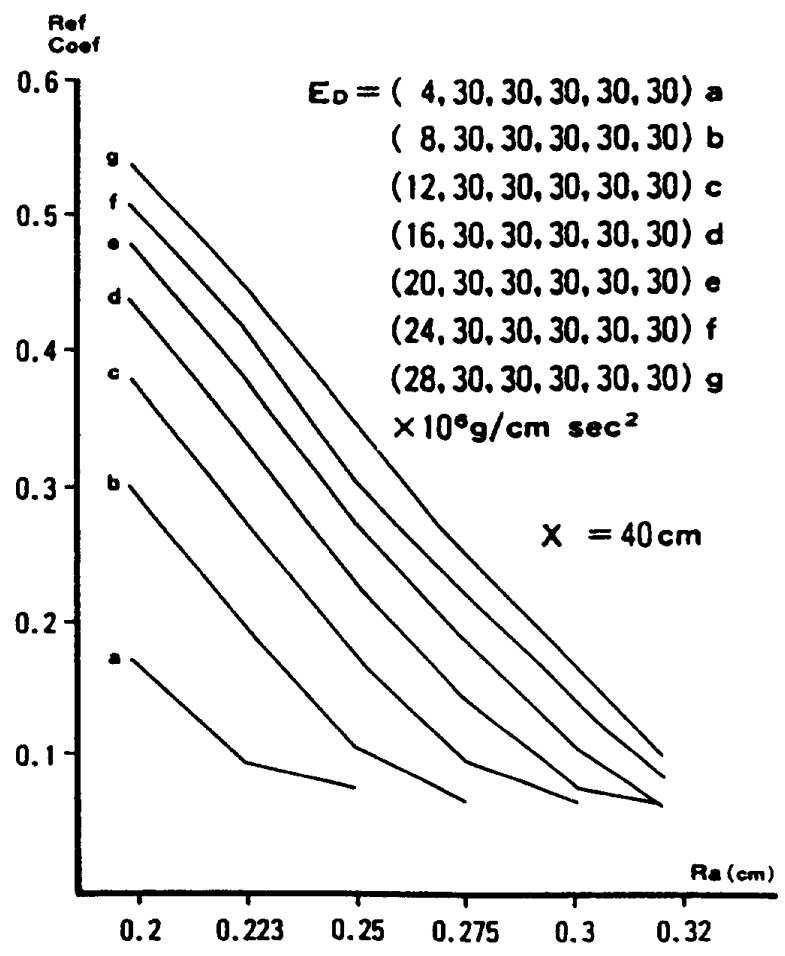

Fig 5-b

Fig 5. The quantitative effects of radius Ra on the Reflection Coefficient with parametric changes in elastic modulus Ed( $f=1)$ at entrance $x=0$ (Fig 5-a) and $x=40 \mathrm{~cm}$ (Fig 5-b). 
Ref $\operatorname{Coef}(f=1)$ vs Eo $(f=1)$

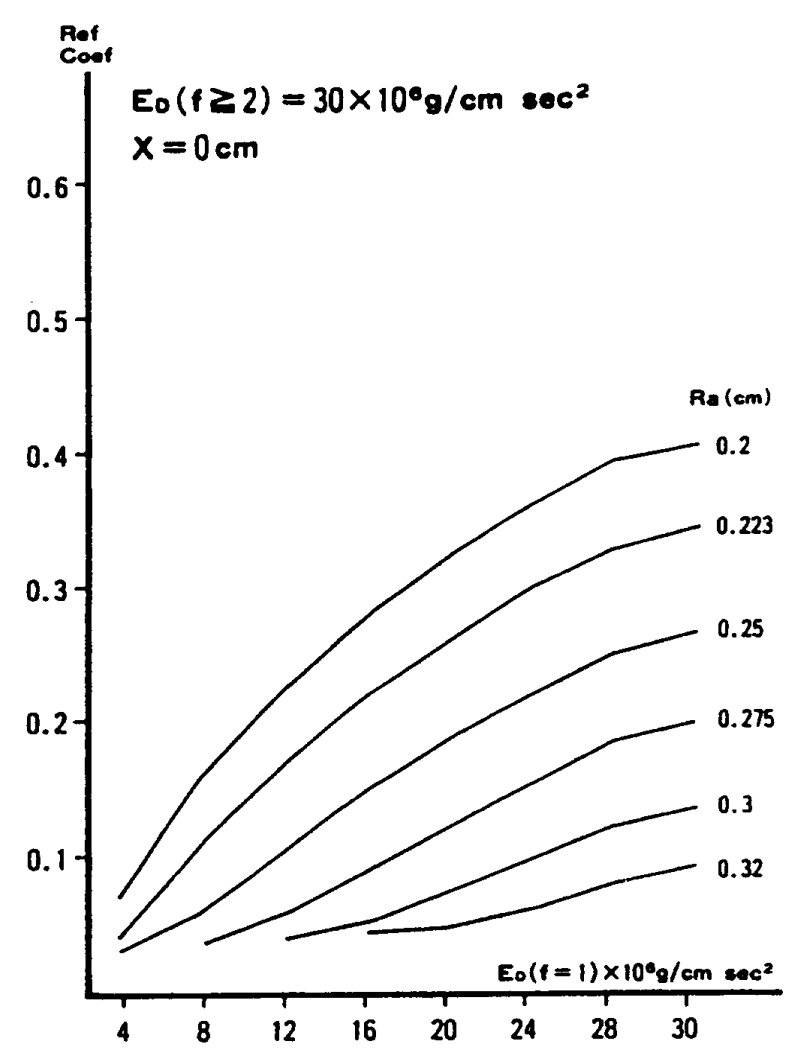

Fig 6-a
Ref $\operatorname{Coef}(f=1)$ vs $E_{0}(f=1)$

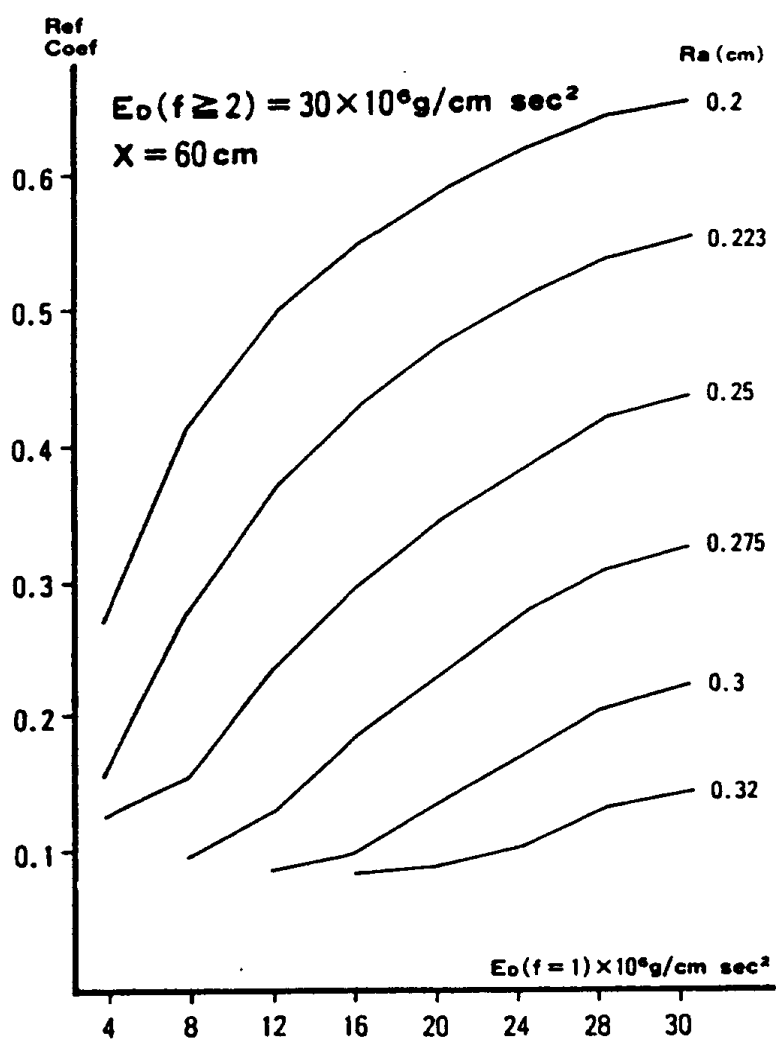

Fig 6-b

Fig 6. The quantitative effects of elastic modulus $\operatorname{Ed}(f=1)$ on the Reflection Coefficient with parametric changes in $\mathrm{Ra}$ at $\mathrm{x}=0 \mathrm{~cm}$ (Fig 6-a) and at $\mathrm{x}=60 \mathrm{~cm}$ (Fig 6-b).

increase in radius, reflection coefficient decreased almost linearly except at $0.275 \mathrm{~cm}<\mathrm{Ra}<0.3 \mathrm{~cm}$. The ratio of its decrease heavily depended on $\mathrm{x}$. A rapid change manifested particularly at near the terminal of arterial tube $(x=60 \mathrm{~cm})$. Similar but more pronounced change manifested at higher elastic modulus $\operatorname{Ed}(\mathrm{f}=1)$ $=30 \cdot 10^{6} \mathrm{~g} / \mathrm{cm} / \mathrm{sec}^{2}$ (Fig 4-b) in which reflection coefficient decreased constantly at entire range of radius.

4. The effect of changes in radius with parametric changes in elastic modulus $\operatorname{Ed}(f=1)$.

Fig 5 expresses the quantitative effects of radius with parametric changes in the first harmonics of the elastic modulus $\operatorname{Ed}(\mathrm{f}=1$ ) at $\mathrm{x}=0 \mathrm{~cm}$ (Fig 5-a) and at $\mathrm{x}=40 \mathrm{~cm}$ (Fig 5-b). The reflection coefficient was larger at larger $\operatorname{Ed}(\mathrm{f}=1)=28 \cdot 10^{6} \mathrm{~g} / \mathrm{cm} / \mathrm{sec}^{2}$ than that at smaller Ed $(f=1)=4 \cdot 10^{6} \mathrm{~g} / \mathrm{cm} / \mathrm{sec}^{2}$ and it decreased almost linearly with radius. At smaller $\mathrm{Ed}(\mathrm{f}=1)=4 \cdot 10^{6} \mathrm{~g} / \mathrm{cm}$ $/ \mathrm{sec}^{2}$, reflection coefficient decreased a little at small radius $0.2 \mathrm{~cm}<\mathrm{Ra}<0.223 \mathrm{~cm}$.

5. The effects of elastic modulus Ed with parametric change in $x$.

At smaller radius $(\mathrm{Ra}=0.223 \mathrm{~cm})(\mathrm{Fig} 6-\mathrm{a})$, the reflection coefficient increased curvilinearly with $\operatorname{Ed}(\mathrm{f}=1)$ at any position of arterial tube. It increased rapidly at smaller $\operatorname{Ed}(\mathrm{f}=1)$ range $\left(4<\operatorname{Ed}(\mathrm{f}=1) 10^{6} \mathrm{~g} / \mathrm{cm} / \mathrm{sec}^{2}<\right.$ 12) while at larger $\operatorname{Ed}(\mathrm{f}=1),\left(24<\operatorname{Ed}(\mathrm{f}=1) 10^{6} \mathrm{~g} / \mathrm{cm}\right.$ $/ \sec ^{2}<30$ ), it increased gradually. Such tendency was markedly depressed at larger radius.

\section{[DISCUSSION]}

Our object was to show the distance dependency of arterial reflection coefficient with isolated effects of elastic modulus and radius of artery based on a transmission line theory (Womersely 1958) under the physiological arterial parameters. The reflection coefficient has increased with distance and elastic modulus of arterial wall while it has decreased with radius. The effects of radius and elastic 
modulus have been heavily depended on the distance. Their individual effects have characteristic features.

Although, reflection coefficient (Womersely 1958, Li, 1984, Campbell 1989) or pulse wave velocity ( $\mathrm{Li} 1981$ ) have been investigated extensively, no quantitative examination about isolated effects of changes in radius, elastic modulus of wall have been reported because in actual arterial system, the intemal radius decreases in size with distance while the elastic modulus increases toward peripheral (Learoyd 1966). Under these circumstances, a theoretical approach is still available. To avoid the complication, analysis has been confined on a femoral artery.

\section{A] The comparison with reported experimental results.}

Sipkema et al. (1975) reported the changes of pressure amplitude in a rubber tube arterial model as a function of the distance to the pump (heart) from $2 \mathrm{~Hz}$ to $16 \mathrm{~Hz}$ with varying terminal loading conditions. Their experimental conditions were physiological and almost the same with present study. Up to $8 \mathrm{~Hz}$, the amplitude of each pressure harmonic wave in the tube with a resistive load 3550 $\mathrm{g} / \mathrm{cm}^{4} \mathrm{sec}$ increased monotonously from the pump to the maximum at the end of tube. This result was in agreement with the peaking of pressure pulse toward the periphery in the arterial system. In their report, the first minimum at the frequencies generated was found at $8 \mathrm{~Hz}$. For lower frequencies, the tube was not long enough for a minimum to be observed. Consequently, though they have analyzed only the changes in pressure pulse, we speculate that the distance dependency of reflection in their experiment must have the similar pattern with our results.

Consistently with their results, the reflection coefficient in the present study did not oscillate between the minimum (node) nor the maximum (antinode) at the interval of a quarter wave length. It was quite natural because the wave length (an imaginary part of $\gamma$ ) in the present analysis has been sufficiently longer than the total length of analyzed arterial model $(\mathrm{L}=60 \mathrm{~cm})$.

About the constitutive nature of artery, only a qualitative comparison with experimental data is available. Present result that a larger radius produces a smaller reflection is consistent with experimental results that, 1) vasodilatation decreases the reflection (O'Rourke and Taylor 1967, MacDonald, 1974 ), 2) the effects of reflection from large arterial branch points contributed small and constant reflections, 3) while the arterioles influenced strongly on reflection which varies with its vasomotor state (Westrehoff 1972).

The contribution of elastic modulus relates to the experimental result of the age dependent disappearance of pressure wave amplification because aorta stiffens with aging. Thus apparently it is derived in the diminution of reflection produced by an improved matching of proximal to distal impedance (O'Rourke 1968). This result is in accordance with present result that large elastic modulus enhances a reflection coefficient.

Unfortunately in these experiments, we could not find any available quantitative, comparable data about the changes in radius and in elastic modulus with distance dependency of reflection coefficient. However, their qualitative effects was consistent with present data.

B] The wave length and a quarter wave length rule.

Certainly our analysis falls between node and antinode with closed end arterial model, in actual arterial system in vivo, the law of the $1 / 4$ wave length is not always a reliable guide. Because, 1) the reflecting sites in the arteries are multiple and widely dispersed. Thus application of a single terminal ending model is only an averaged result. 2) the reflection usually accompanies the phase shift which also shifts an impedance minimum or pressure node falls at exactly at a quarter of wave length from the reflection site. This effect may be derived in viscosity in wall and blood. 3) the non-uniform elasticity of artery would modify the amplitude of traveling waves.

Therefore present analysis seems to be the first step for reflection coefficient in an entire arterial system. However the clarifications of isolated effects of radius and elasticity of wall with their relations to the distance will afford the basic information for creating physiological artificial vessel.

\section{[ CONCLUSION ]}

1. The reflection coefficient in a segmental artery with constant geometry and a single terminal increased toward the end of arterial tube. It was enhanced by the elastic modulus of wall and diminished by radius.

2 . The reflection coefficient increased rapidly at near the end while it changed gradually at the entrance zone.

3. Present theoretical results were consistent with those of physical experiments performed under the physiological conditions which were identical with present theoretical 
analysis.

4. Present results would be available for creating more physiological artificial vessel.

\section{[ APPENDIX ]}

By setting Womersely's frequency parameter $\alpha=\operatorname{Ra} \omega \rho$ $/ \mu$ and $\mathrm{y}=\mathrm{r} / \mathrm{Ra}$, flow rate $\mathrm{W}$ is

$$
\mathrm{W}=\frac{\mathrm{A}}{\rho \mathrm{C}}\left(1+v \frac{\mathrm{Jo}\left(\sqrt{(\mathrm{i})^{3} \alpha^{2} \mathrm{y}^{2}}\right)}{\mathrm{Jo}\left(\sqrt{(\mathrm{i})^{3}\left(\alpha^{2}\right)}\right)}\right) \exp (i \omega(\mathrm{t}-\mathrm{z} / \mathrm{C}))
$$

where $\operatorname{Jo}(z)$ is 0 -th order Bessel function, $A$ is the coefficient of pressure gradient $(\partial \mathrm{P} / \partial \mathrm{z}=\mathrm{A} \exp (\mathrm{i} \omega \mathrm{t}))$, and

$$
\begin{aligned}
& v=\frac{2}{\lambda(\mathrm{F} 10(\alpha)-2 \alpha)}-\frac{1-2 \sigma}{(\mathrm{F} 10(\alpha)-2 \alpha)} \text { where } \\
& \mathrm{F} 10(\alpha)=\frac{2 \mathrm{~J} 1\left(\sqrt{(\mathrm{i})^{3} \alpha^{2}}\right)}{\sqrt{(\mathrm{i})^{3}} \alpha \mathrm{Jo}\left(\sqrt{(\mathrm{i})^{3} \alpha}\right)} \\
& \text { and } \lambda=\frac{\mathrm{H}}{\mathrm{R}_{\mathrm{a}}}\left(1-\frac{\mathrm{K} 1}{\omega^{2}}\right) \frac{\mathrm{E}_{\mathrm{d}}}{1-\sigma^{2}} \frac{1}{\left(\rho \mathrm{C}^{2}\right)}
\end{aligned}
$$

By areal integration of $W$ at a cross section, arterial blood flow rate $Q$ is calculated as

$\mathrm{Q}=\pi \mathrm{Ra}^{2} \mathrm{~A}\left[1+\nu 2 \mathrm{~J} 1\left(\alpha \mathrm{i}^{3 / 2}\right) /\left(\alpha \mathrm{i}^{3 / 2} \mathrm{Jo}\left(\alpha \mathrm{i}^{3 / 2}\right)\right)\right]$ $/(\mathrm{i} \omega \rho)$.

By utilizing the definition of $\mathrm{F}_{10}(\alpha), \mathrm{Q}$ can be expressed in terms of pressure gradient as

$\mathrm{Q}=\pi \mathrm{Ra}^{2}\left(1+\nu \mathrm{F}_{10}(\alpha)\right)(-\alpha \mathrm{P} / \alpha \mathbf{z}) /(\mathrm{i} \omega \rho)$.

The complex longitudinal impedance is

$\mathrm{Zl}=(-\alpha \mathrm{P} / \alpha \mathrm{Z}) / \mathrm{Q}=\mathrm{i} \omega \rho /\left[\left(\pi \mathrm{Ra}^{2}\right)\left(1+\nu \mathrm{F}_{10}(\alpha)\right)\right]$

The $1 /\left(1+\nu F_{10}(\alpha)\right)$ can be decomposed into the real Re and the imaginary part Im such that

$\mathrm{Zl}=\left(-8 \mu /\left(\pi \mathrm{Ra}^{4}\right) \alpha^{2} / 8\right)^{*} \mathrm{Im}+\mathrm{i} \omega \rho /\left(\pi \mathbf{R a}^{2}\right) * \operatorname{Re}$ $=\mathrm{R}(\omega)+$ in $\mathrm{L}(\omega)$

Therefore, flow rate $Q$ can be regarded as a function of angular velocity $\omega=2 \pi \mathrm{f}$

$$
-\partial \mathrm{P} / \partial \mathrm{z}=\mathrm{R}(\omega) \mathrm{Q}+\mathrm{L}(\omega) \partial \mathrm{Q} / \partial \mathrm{t}
$$

The transverse impedance on the other hand can be

$\mathrm{Zt}=-\mathrm{P} /(\partial \mathrm{Q} / \partial \mathrm{z})$

It can be represented in terms of complex as

$\mathrm{Zt}=1 /(\mathrm{i} \omega \mathrm{Cp})$

where $\mathrm{Cp}$ is the compliance of arterial wall and is a function of $\operatorname{Ed}(f)$. Its definition is

$\mathrm{Cp}=\left[(5-4 \sigma)(\mathrm{Ra} / \mathrm{h})^{2}+4(1+\sigma) \mathrm{Ra} / \mathrm{h}+2(1+\sigma)\right]$ / $[\operatorname{Ed}(\omega)(2 \mathrm{Ra} / \mathrm{h}+1)]$

Then the pressure and flow rate at radial direction was

$-\partial \mathrm{P} / \partial \mathrm{t}=\partial \mathrm{Q} / \partial \mathrm{z} /(\mathrm{Cp}(\omega))$

Equation (16) and (18) should be converted into transmission line equations by converting pressure to voltage $\mathrm{V}(\mathrm{t}, \mathrm{x})$ and flow to current $\mathrm{I}(\mathrm{t}, \mathrm{x})$, assuming Fourier form linear cyclic solutions as

$V(t, x)=V(x) \exp (i \omega t), \quad I(t, x)=I(x) \exp (i \omega t)$

Then

$-\partial V(x) / \partial x=(R(\omega)+i \omega L(\omega)) I(x)$
$-\partial I(x) / \partial x=i \omega C p(\omega) V(x)$

By differentiating (24) and (25) mutually and eliminating the $\mathrm{I}(\mathrm{x})$, Above equations

$$
\partial^{2} \mathrm{~V}(\mathrm{x}) / \partial \mathrm{x}^{2}=(\mathrm{R}(\omega)+\mathrm{i} \omega \mathrm{L}(\omega)) \mathrm{i} \omega \mathrm{Cp}(\omega) \mathrm{V}(\mathrm{x})
$$

which is a second order differential equation of $V(x)$ with complex variable.

\section{[ REFERENCES ]}

1) Womersely J.R. : An elastic tube theory of pulse transmission and oscillatory flow in arteries. WADC. Technical Report. 56. 614. 1957. 
2) MacDonald : Blood flow in Artery. chapter 12. Arnold 1974.

3) Li, J. K., Melbin, R., Riffle, A., Norrdergraaf, A. : Pulse wave propagation. Cir. Res. vol 49. pp 441-452. 1981.

4) Sakamoto, T., Saito, M., Nakayama, K. : Analysis of motion of viscous liquid in a thin walled elastic tube. Medical electronics and Bio-engineer. vol 1. pp 408413. 1966.

5) Patel, D. J., Fry, D. L. : Longitudinal tethering of arteries in dogs. Cir. Res. vol 19. pp 1011-1021. 1966.

6) Sipkema, P., Westerhoff, N. : Effective length of the arterial system. Annals of Biomedical Engineering. vol 3. pp 296-307. 1975.

7) Womersely, J. R. : Oscillatory flow in arteries. II. Physics in Medicine and Biology. vol 2. pp 313-323. 1958.

8) Li, J. K., Melbin, J., Noordergraaf, A. : Directional disparity of pulse reflection in the dog. Am. J. Physiol. vol 247. H95-99. 1984.

9) Campbell, K. B., Noordergraaf, A. : Pulse reflection sites and effective length of the arterial system. Am. J. Physiol. vol 256. h 1684-1689. 1989.

10) Learoyd, B. M., Taylor, M. G. : Alteration with age in the visco-elastic properties of human arterial system. Cir. Res. vol 28. pp 278-292. 1966.

11) Atabeck H.B. : Wave propagation through a viscous fluid contained in a tethered, initially stressed orthotropic elastic tube. Biophysical J. vol 8. pp 626-
649. 1968.

12) Tickner, E. G., Sacks, A. H. : A theory for the static elastic behavior of blood vessel. Biorheology. vol 4 . pp 151-168. 1967.

13) Carew, T. E., Vaishnov, R. N., Patel, D. J. : Compressibility of the arterial wall. Cir. Res. vol 23. pp 61-68. 1968.

14) O'Rourke, M. F., Taylor, M. G. : Input impedance of the systemic circulation. Cir. Res. vol 20. pp 365-380. 1967.

15) Westerhoff, N., Sipkema, P., Bos, van den, Elzingar, G. : Forward and backward waves in the arterial system. Cardiovascular Res. vol 6. pp 648-656. 1972.

16) O'Rourke, M. F. : Impact pressure, lateral pressure and impedance to the proximal aorta and pulmonary artery. J. Appl. Physiol. vol 25. pp 533-541. 1968.



Hirohumi, Hirayama received the M.D degree in Neurophysiology from Hokkaido University in 1985. He worked as a cardiologist in Hokkaido University from 1985 to 1990 and is now an assistant professor at Department of Public Health in Asahikawa Medical College. His main theme is optimal modeling of biological system. He is a member of S.I.C.E., J.S.M.E., J. Applied Physics, M.E., J. Circulation Society, J. Society of Anesthesiology. 